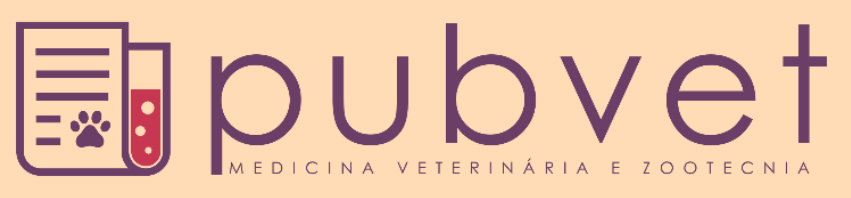

https://doi.org/10.31533/pubvet.v13n10a422.1-12

\title{
Biomarcadores reprodutivos no proteoma do sêmen de touros
}

\author{
Daniel Fábio Salvador ${ }^{1 *}$, Sandro César Salvador ${ }^{2}$ \\ ${ }^{1}$ Professor Fundação Centro de Ciências e Educação Superior a Distância do Estado do Rio de Janeiro, - RJ, Brasil. \\ ${ }^{2}$ Professor Universidade Federal do Rio de Janeiro, Rio de Janeiro - RJ, Brasil. \\ *Autor para correspondência, E-mail: salvador@cecierj.edu.br
}

Resumo. A avaliação do perfil bioquímico de proteínas do sêmen abriu novas fronteiras a partir da década de 90 na busca por marcadores associados ao potencial reprodutivo de touros. Esta revisão de literatura apresenta os fundamentos fisiológicos e bioquímicos básicos dos mecanismos de atuação das proteínas do sêmen e como afetam eficiência da criopreservação de gametas e fecundação em reprodutores bovinos. Apresentam-se os achados dos últimos 50 anos de pesquisas na área, bem quanto as atuais limitações, aplicações e perspectivas futuras, tanto para raças europeias, quanto zebuínas. Destaca-se o potencial como biomarcadores reprodutivos das chamadas proteínas ligadas aos espermatozoides (Binder of SPerm proteins - BSP), que se referem a um amplo grupo de proteínas que se ligam aos espermatozoides no momento da ejaculação, promovendo o início da capacitação, principalmente na presença de heparina. Também são descritos os resultados das principais pesquisas que buscaram pelas associações entre proteínas do sêmen com fertilidade e sucesso na criopreservação. Nas conclusões são apresentadas algumas das aplicações, impactos e perspectivas futuras para as pesquisas da área.

Palavras chave: Touros, andrologia, fertilidade, desempenho reprodutivo, sêmen, proteínas, HPB, BSP

\section{Reproductive biomarkers in bull semen proteome}

Abstract. The semen protein biochemical evaluations profile opened new frontiers from the $90 \mathrm{~s}$ in the research about reproductive markers associated with bulls potential. This literature review presents the basic physiological and biochemical foundations of semen protein mechanisms and how they affect gamete cryopreservation efficiency and fecundation in bulls. We present the findings of the last 50 years of research in the area, as well as the current limitations, applications and future prospects for both European and Zebu breeds. We highlighted the potential as reproductive biomarkers of the Binder of SPerm proteins (BSP), which refer to a broad group of proteins that bind to sperm at the time of ejaculation, promotes sperm capacitation, especially in heparin presence. The results of the main researches that searched for associations between semen proteins with fertility and success in cryopreservation are also discussed. The conclusions present some of the applications, impacts and future perspectives for researches in this area.

Keywords: Andrology, bulls, fertility, reproductive performance, sperm, proteins, HPB, BSP

\section{Biomarcadores reproductivos en el proteoma del semen de toro}

Resumen. La evaluación del perfil bioquímico de la proteína del semen abrió nuevas fronteras a partir de los años 90 en la búsqueda de marcadores asociados con el potencial reproductivo de los toros. Esta revisión de la literatura presenta los fundamentos fisiológicos y bioquímicos de los mecanismos de la proteína del semen y cómo afectan la eficiencia de la criopreservación de los gametos y la fecundación en los reproductores 
bovinos. Presentamos los resultados de los últimos 50 años de investigación en el área, así como las limitaciones actuales, las aplicaciones y las perspectivas futuras para las razas europeas y cebú. Destacamos el potencial como biomarcadores reproductivos de las llamadas proteínas Binder of SPerm (BSP), que se refieren a un amplio grupo de proteínas que se unen a los espermatozoides en el momento de la eyaculación, promoviendo el inicio de la capacitación, principalmente en presencia de heparina También se describen los resultados de las principales investigaciones que buscaron asociaciones entre las proteínas del semen con la fertilidad y el éxito en la criopreservación. Las conclusiones presentan algunas de las aplicaciones, impactos y perspectivas futuras para la investigación en el área.

Palabras clave: Toros, andrología, fertilidad, rendimiento reproductivo, semen, proteínas, HPB, BSP

\section{Introdução}

Exames complementares envolvendo marcadores bioquímicos, avaliação da qualidade espermática e capacidade de fecundação, tem amplo potencial de fornecer melhores subsídios para seleção de touros de ótimo desempenho reprodutivo, além de poderem atuar como marcadores genéticos para alta fertilidade em touros. Neste contexto, a avaliação do perfil bioquímico de proteínas do sêmen abriu novas fronteiras na busca por biomarcadores associados ao potencial reprodutivo (Ax et al., 2002; Druart \& Graaf, 2018; Rodríguez-Martínez et al., 2011). Diferenças marcantes são relatadas entre touros com o mesmo padrão andrológico e qualidade espermática, tanto para fertilidade a campo, quanto para eficiência nos processos de congelação de sêmen e de fecundação "in vitro" (Feliciano Silva, 1998; (Bellin et al., 1998; Camargo et al., 2002; Ollero et al., 1998; Sprott et al., 2000). Estes estudos trazem à tona a necessidade de uma melhor compreensão de todos os fatores que interferem na fertilidade de touros quanto à capacidade fecundante do espermatozoide, sendo necessário um maior direcionamento das pesquisas neste sentido.

A seleção andrológica baseada apenas nos exames andrológicos de rotina de qualidade espermática e biometria testicular serve como critério preliminar para a escolha de reprodutores bovinos, eliminando aqueles de baixa fertilidade. Essas avaliações andrológicas micro ou macroscópicas sem dúvida são ótimos indicadores da qualidade espermática de um reprodutor, eliminando e descartando situações patológicas, bem como identificando os animais com padrões regulares ou ótimos de produção espermática viável a fecundação. Entretanto, as mesmas por si só raramente são capazes de diferenciar touros de médio o alto potencial de fertilidade (Garner, 1997). Ressalta-se, entretanto, que a seleção andrológica preliminar jamais poderá ser substituída ou eliminada do processo de escolha e seleção de touros de alta fertilidade, uma vez que os exames andrológicos de rotina são passos essenciais para qualquer outro exame complementar de predição da fertilidade em bovinos. Entretanto, visando a identificação de touros de alta fertilidade torna-se necessário, a aplicação de técnicas mais sofisticadas relacionadas à qualidade funcional do espermatozoide e aos mecanismos fisiológicos envolvidos na fertilização e aos processos bioquímicos da fertilidade (Blottner et al., 1990). Apesar de não totalmente elucidados todos os seus mecanismos de atuação, é certo que as proteínas do plasma seminal têm amplo panorama de ação fisiológica e bioquímica no sêmen de mamíferos, e possuem parcela significante de responsabilidade sobre o sucesso de fertilidade de touros (Druart \& Graaf, 2018; Rodríguez-Martínez et al., 2011). Por esse motivo apresentamos aqui uma revisão de literatura com objetivo de relatar o atual estado das pesquisas na busca de proteínas seminais como biomarcadores da reprodução de touros.

\section{Capacitação espermática, reação acrossômica e fecundação}

Embora o reprodutor ejacule bilhões de espermatozoides no trato reprodutivo feminino, apenas um total de 1.000 a 10.000 chega até o ístimo e apenas 10 a 100 destes estarão na ampola após quatro a doze horas da ejaculação. Isto é resultante de um movimento controlado na junção útero tubárica, o qual regula o número de espermatozoides no local da fertilização, além de garantir um reservatório para os mesmos (Hafez \& Hafez, 2004; Kopf, 1999). Os espermatozoides, quando presentes na ampola, tornamse hiperativos aumentando a probabilidade de encontrar o óvulo. Apesar da heterogeneidade na população de espermatozoides, todos os espermatozoides vivos encontrados na ampola são capacitados e se tornam hábeis para a fertilização do óvulo. Isto sugere que a seleção de um pequeno número de 
espermatozoides capacitados, que chega até a ampola, ocorre ao longo do trato reprodutivo feminino, mediante vários processos específicos (Yanagimachi, 1988). Dentro deste contexto sabe-se também que a fertilização em mamíferos envolve a interação entre o espermatozoide e a matriz extracelular do óvulo (zona pelúcida). O resultado desta interação é dependente do estádio final de maturação do espermatozoide. A maturação é um processo com vários passos, incluído a capacitação espermática e a reação acrossômica (Yanagimachi, 1988).

A capacitação é o processo no qual o espermatozoide passa por uma série de mudanças metabólicas e bioquímicas, no trato reprodutivo da fêmea, as quais induzem a reação acrossômica. Em condições naturais, este processo parece ocorrer na junção útero tubárica, levando menor ou maior tempo, dependendo da espécie, mas sempre como um pré-requisito para a fecundação (Hafez \& Hafez, 2004; Kopf, 1999). Quando o processo de capacitação é ativado, é um processo sem volta, ou seja, o espermatozoide que iniciou capacitação não pode parar mais a sequência de eventos que vai culminar na reação acrossômica, como estágio final para penetração e fecundação. Isso leva a crer que existe a necessidade de mecanismos que impeçam a capacitação espermática precoce, ou seja, que ela ocorra muito antes da interação entre espermatozoide e oócito. Esses mecanismos estão ligados a mudanças bioquímicas que envolvem o plasma seminal (Rickard et al., 2019; Suarez, 2016). Em bovinos a reação acrossômica ocorre somente em espermatozoides capacitados (Florman \& First, 1988). Deste modo, pode-se dizer que a capacitação é um ato regulatório da reação acrossômica induzida pelas glicoproteínas da matriz extracelular (Wassarman, 1988). Todas essas mudanças permitem a progressão dos três principais passos da fertilização, que são a hiperativação espermática, o reconhecimento específico entre espermatozoide e a zona pelúcida e a fusão dos gametas.

Os proteoglicanos, assim como outros componentes da matriz extracelular, influenciam a adesão, motilidade, proliferação, crescimento e diferenciação de muitas células (Ratner et al., 1985). Os proteoglicanos da matriz extracelular têm como parte central os glicosaminoglicanos (GAGs) envolvidos também na fertilização na maioria das espécies. Em bovinos os GAGs, e em especial a heparina do oviduto, promovem a capacitação do espermatozoide do touro (Ax \& Lenz, 1987; Parrish et al., 1988). No trato reprodutivo feminino, a capacitação espermática ocorre sempre diante de altas concentrações de GAGs do fluído folicular ovariano ou de outras fontes (Parrish et al., 1989). A ligação da heparina ao espermatozoide é saturável (receptor com pontos de ligação), reversível e dependente do $\mathrm{pH}$, temperatura e nível de $\mathrm{Ca} 2+$. A concentração de heparina necessária para a capacitação é semelhante ao requerido para saturar os pontos de ligação (Handrow et al., 1984; Miller et al., 1990).

A capacitação do espermatozoide bovino estimulado pelos GAGs necessita da maturação induzida pelo plasma seminal (Florman \& First, 1988; Lee et al., 1985), visto que o plasma seminal aumenta os locais de ligação da heparina no espermatozoide epididimário (Lee et al., 1985), além de possuir proteínas ligadoras de heparina (HPB) (Miller et al., 1990). Esse não parece ser o único mecanismo de ativação da capacitação espermática, porém é com certeza um deles, senão um dos mais importantes. A indução artificial da reação acrossômica tem como principais indutores descritos a heparina, lisofosfatidilcolina (LPC) e inonóforo de cálcio (Assumpção et al., 2002; Kitiyanant et al., 2002; Parrish et al., 1988).

Nos processos de fecundação "in vitro" (FIV), ou seja, técnicas de maturação e fecundação dos oócitos e cultivo embrionário, os resultados de desempenho entre touros de qualidade espermáticas aparentemente iguais, indicam alta variabilidade (Blottner et al., 1990; Camargo et al., 2002). Estes resultados têm mostrado a possibilidade da aplicação das técnicas de fertilização "in vitro", para a predição da fertilidade dos touros (Fazeli et al., 1993; Lonergan, 1994; Rodriguez-Martinez et al., 1997).

\section{Proteínas do plasma seminal e membrana espermática}

Alguns estudos clássicos na década de 90 (Bellin et al., 1994; Killian et al., 1993; Manjunath et al., 1994) demostraram a existência de proteínas do plasma seminal que são fundamentais para os processos biológicos da fecundação. Neste contexto, a avaliação do perfil de proteínas ligadas aos espermatozoides (Binder of SPerm proteins - BSP), em especial as com afinidade a heparina (HBP) do sêmen de touros têm aberto novas fronteiras como avaliações reprodutivas complementares (Ax et al., 2002). Depois de mais de 30 anos de pesquisas correlacionando o perfil proteico do sêmen com a fertilidade de touros e sucesso no congelamento do sêmen, com resultados iniciais vislumbrou-se um amplo horizonte de 
utilização de tais proteínas como testes complementares aos exames de rotina e até mesmo como potenciais marcadores genéticos para alta fertilidade e congelamento do sêmen (Bellin et al., 1998; Jobim et al., 2004; Ollero et al., 1998). No entanto, para um melhor detalhamento dos processos bioquímicos e fisiológicos envolvidos com preparação do espermatozoide para fecundação sabe-se que existe um longo caminho a percorrer, com diversos mecanismos ainda não elucidados (Druart \& Graaf, 2018; Rodríguez-Martínez et al., 2011; Sutovsky et al., 2019).

As proteínas do sêmen nos animais domésticos podem ser de origem testicular, epididimária ou produzidas pelas sexuais acessórias, podendo permanecer no fluído seminal ou ainda se ligarem a membrana espermática durante a ejaculação com atividades biológicas diversas relacionadas à fecundação. Vários pontos precisam ser considerados antes das análises descritivas de proteínas e enzimas do plasma seminal, uma vez que fatores físicos externos e clínicos do animal podem alterar completamente a composição proteica do sêmen. A centrifugação pode provocar a passagem de proteínas do meio intracelular para o extracelular, provocando erros das análises. Já os distúrbios clínicos das glândulas acessórias levam ao aumento de constituintes nitrogenados não proteicos.

O tempo de estocagem do sêmen a $37^{\circ} \mathrm{C}$, também pode mudar completamente o perfil proteico, permitindo a ação proteolítica que quebra várias proteínas em suas subunidades. Sem controle destes fatores pode haver conclusões erradas da determinação quantitativa e eletroforética das proteínas do sêmen (Mann \& Mann, 1981). Os principais grupos de proteínas no sêmen relatados por Mann \& Mann (1981) para a maioria das espécies, foram as proteínas ligadas ao cálcio, proteínas ligadas ao zinco, lactoferinas, transferinas, hormônios protéicos, enzimas proteolíticas e lipolíticas, nucleases, nucleotidases, nucleosidades, fosfatases, glicosidases, sulfidril oxidases e glicoproteínas, além de outros peptídeos, aminoácidos e bases nitrogenadas. As proteínas e glicoproteínas de origem testicular são na sua maioria reabsorvidas durante o trajeto epididimário, desaparecendo após a passagem pela cauda do epidídimo, não sendo registradas em grandes quantidades no plasma seminal. Um exemplo disto é o caso das proteínas clusterina e transferina que são achadas no fluido da "rete testis"; porém, são reabsorvidas no epidídimo (Gatti et al., 2004). De forma geral, existem mais de 50 proteínas secretadas no epidídimo, identificadas em 15 espécies estudadas, sendo aproximadamente 20 por espécie, com várias delas encontradas em mais de uma espécie. Os principais grupos de proteínas encontrados são as proteínas ligadas a pequenas moléculas hidrofóbicas, proteínas ligadas a lipídios, proteínas ligadas ao ferro, glicosidases, enzimas antioxidantes, proteases e inibidores de proteases, clusterinas, dentre outras de função desconhecida (Dacheux \& Dacheux, 2002).

Em bovinos, as principais proteínas epididimárias relatadas foram a "proteína tranportadora de colesterol" (CTP) $(27 \mathrm{kDa})$, a clusterina $(66-77,32-41 \mathrm{kDa})$, a prostaglandina D-sintetase (35 kDa), a mannosidase $(135 \mathrm{kDa})$, a hexosaminidase $(64 \mathrm{kDa})$ e a Galactosidase $(63 \mathrm{kDa})$, sendo que somente estas representam 80 a $90 \%$ do total de proteínas secretadas no epidídimo (Dacheux \& Dacheux, 2002; Gatti et al., 2004). Outras importantes fontes de proteínas para o plasma seminal são os órgãos sexuais acessórios. No touro a vesícula seminal é o órgão sexual acessório mais ativo, produzindo a maior parte do plasma seminal ejaculado (Maxwell et al., 2007). Uma importante proteína do plasma seminal secretada pelas glândulas vesiculares é a "Proteína ácida do plasma seminal" (aSFP) (Einspanier et al., 1991). Dentre as suas atividades biológicas estão à atuação como fator decapacitante, a preservação da integridade acrossômica e a regulação da motilidade espermática e mitocondrial.

Sabe-se que proteínas do plasma seminal se prendem a membrana espermática, facilitando a ligação com a heparina e outros GAGs, estimulando assim a capacitação do espermatozoide. O papel regulatório das proteínas ligadoras de heparina (HBP) sobre a capacitação do espermatozoide bovino foi evidenciado por Miller et al. (1990). Os autores, usando a técnica "Western Bloting", confirmaram a afinidade pela heparina e a ligação com o espermatozóide epididimário das proteínas do sêmen de 1418, 24 e $31 \mathrm{kDa}$. Posteriormente, seguindo a mesma linha de pesquisa, Bellin et al. (1994) avaliaram o perfil de proteínas com afinidade a heparina do sêmen de touros em algumas raças de corte. Os touros foram examinados em função da presença ou ausência de HBPs na membrana espermática e fluído seminal. As amostras foram analisadas somente pela afinidade a heparina em cromatografia líquida de alta performance (HPLC), com cinco picos de proteínas detectados. Já Bellin et al. (1998) propuseram em um levantamento de identificação das proteínas com afinidade a heparina (Tabela 1), feito em 2191 touros considerados aptos a reprodução, um modelo com formação de quatro categorias com as 
seguintes frequências encontradas: Grupo A: Proteínas com peso molecular de 21,5, 24 e $30 \mathrm{kDa}$ (FAA); Grupo B: Proteínas com peso molecular de 21,5 e $30 \mathrm{kDa}$ (FAA); Grupo C: Proteínas com peso molecular de 21,5 kDa; Grupo D: Sem nenhuma destas proteínas.

Tabela 1. Levantamento do perfil de antígeno associado a fertilidade (FAA) em touros de diversas raças bovinas

\begin{tabular}{|c|c|c|c|c|c|c|}
\hline \multirow{2}{*}{ Raças } & \multirow{2}{*}{ Número de rebanhos } & \multirow{2}{*}{ Número de touros } & \multicolumn{4}{|c|}{ Touros em cada tipo de perfil FAA, $\%$} \\
\hline & & & A & $\mathrm{B}$ & $\mathrm{C}$ & $\mathrm{D}$ \\
\hline Angus & 3 & 141 & 33 & 55 & 6 & 6 \\
\hline Brahman & 2 & 73 & 45 & 48 & 7 & 0 \\
\hline Brangus & 3 & 88 & 56 & 35 & 9 & 0 \\
\hline Braunvieh & 1 & 14 & 57 & 36 & 0 & 7 \\
\hline Charolês & 4 & 148 & 55 & 34 & 8 & 2 \\
\hline Gelbvieh & 1 & 10 & 100 & 0 & 0 & 0 \\
\hline Hereford & 3 & 393 & 61 & 38 & 1 & 0 \\
\hline Holstein & 3 & 36 & 67 & 33 & 0 & 0 \\
\hline Red Angus & 1 & 69 & 62 & 26 & 7 & 4 \\
\hline Santa Cruz & 1 & 258 & 47 & 39 & 6 & 8 \\
\hline Santa Gertrudis & 1 & 235 & 57 & 23 & 6 & 15 \\
\hline Santa Gertrudis & 7 & 133 & 45 & 45 & 6 & 4 \\
\hline Simental & 1 & 103 & 5 & 46 & 36 & 14 \\
\hline Simental & 1 & 18 & 72 & 11 & 6 & 11 \\
\hline Cruzados & 7 & 142 & 78 & 13 & 4 & 6 \\
\hline Cruzados & 5 & 357 & 37 & 50 & 12 & 1 \\
\hline Total & 44 & 2191 & 50 & 38 & 7 & 5 \\
\hline
\end{tabular}

Fonte: Bellin et al. (1998).

No mesmo estudo, Bellin et al. (1998) citam a HBP de 30-31 kDa, como uma das de maior importância como marcador bioquímico para fertilidade, sendo denominada "antígeno associado a fertilidade" (FAA), descrita mais tarde por McCauley et al. (1999) como proteínas semelhante a Dnase I - humana, presente no plasma seminal e aderida a membrana espermática. As proteínas HBP encontradas ligadas a membrana espermática são parte do grupo de proteínas denominadas Binder of SPerm proteins (BSP), que são proteínas que ligam aos espermatozoides no momento da ejaculação promovendo o início da capacitação, principalmente na presença de Heparina. Entretanto, as FAA descritas por Bellin et al. (1994) pode ser considerado um biomarcador mais específico dentre as BSPs.

Killian et al. (1993) avaliaram o perfil eletroforético uni- e bi- dimensional de proteínas do plasma seminal de bovinos, registrando quatro proteínas importantes associadas à fertilidade $(55 \mathrm{kDa}$ e 4,8pI; $26 \mathrm{kDa}$ e $6,4 \mathrm{pI} ; 16 \mathrm{kDa}$ e 4,1pI; $16 \mathrm{kDa}$ e 6,7pI). Em pesquisas posteriores estas proteínas foram isoladas e submetidas ao sequenciamento $\mathrm{N}$-terminal de aminoácidos. A proteína para alta fertilidade de $55 \mathrm{kDa}$ e 4,8 pI foi $86 \%$ homologa ao precursor da osteopontina - K (Cancel et al., 1997). Já Gerena et al. (1998), estudando a proteína de $26 \mathrm{kDa}$ e 6,4PI, descrita por Killian et al. (1993) mostraram que ela é $75 \%$ idêntica e $100 \%$ homologa ao tipo lipocalin prostaglandina-D-sintetase (PGDS), uma das proteínas mais prevalentes nos touros de alta fertilidade.

É interessante também citar que Killian et al. (1999) concluíram que possivelmente as duas proteínas com maior prevalência nos touros de baixa fertilidade ( $16 \mathrm{kDa}$ com 4,1 $\mathrm{pI}$ e $16 \mathrm{kDa}$ com 6,7 pI), possam estar associadas com o Micoplasma genitalium, um microrganismo normalmente presente na genitália do macho. Ou seja, em analisando o perfil proteico do sêmen de touros é importante estar atendo aos fatores não endógenos que podem afetar o resultado.

Visando também elucidar o papel do plasma seminal sobre a fertilidade, Manjunatha \& Srinivasan (2006) caracterizaram e purificaram a família de proteínas designadas coletivamente de proteínas do plasma seminal bovino - BSP: BSP-A1, BSP-A2, BSP-A3 (com peso molecular variando de 15 a 16,5 $\mathrm{kDa}$ ) e BSP- $30 \mathrm{kDa}$ (com peso molecular entre 28-30 kDa). Essas proteínas são secretadas pelas glândulas vesiculares, agrega-se à superfície do espermatozoide após a ejaculação ligando-se a 
apolipoproteínas (apoA-1), bem como a apoA-1 associada com lipoproteínas de alta densidade (HDL), calmodulin e heparina (Manjunath et al., 1994). As proteínas BSP também se ligam aos fosfolípides colina, que compreendem os principais lipídios da membrana espermática, o que sugere que estes lipídios podem ser pontos de ligação das proteínas BSP com a membrana espermática (Desnoyers \& Manjunath, 1992).

Os seguintes mecanismos teóricos são propostos diante das pesquisas descritas (Manjunath et al., 1994). Primeiro, após a ejaculação, as proteínas BSP cobrem a superfície do espermatozoide, interagindo com os fosfolípides que contém fosforilcolina no grupo da cabeça. Isso talvez promova a decapacitação espermática, prevenindo a reação acrossômica prematura, até este espermatozoide adentrar o trato reprodutivo feminino e se encontrar com os HDLs ou com a heparina. Em um segundo passo, os HDLs acomodam as proteínas BSP ligadas à membrana espermática. No terceiro momento, as proteínas BSP sequestram o colesterol e alguns fosfolípides. A perda de lipídeos pode resultar em alterações da permeabilidade da membrana espermática e entrada do cálcio para ativação da fosfolipase A2. Esta converte fosfolípides em lisofosfolípides, que desestabilizam a membrana para posterior fusão. Diante dessas possibilidades as proteínas BSP, não teriam somente função decapacitante, mas poderiam eventualmente promover a capacitação do espermatozoide. Em pesquisas posteriores os autores concluíram que a mediação da capacitação espermática pode ser modulada tanto pela ligação com a heparina (Therien et al., 1995), como pelas lipoproteínas de alta densidade (Therien et al., 1997) na presença da proteína BSP, mas promovidas por diferentes mecanismos (Lane et al., 1999).

Marques et al. (2000) analisando o perfil eletroforético da membrana de espermatozoides de touros de raças zebuínas e europeias, observaram diferenças quantitativas em oito indivíduos analisados. Em quatro touros houve variações de intensidade de proteínas de baixo peso molecular de 14 a $21 \mathrm{kDa}$, com prevalência das bandas 16 e $18 \mathrm{kDa}$. Três touros apresentaram menor intensidade da banda de $30 \mathrm{kDa}$, e um da banda $32 \mathrm{kDa}$. Já outros dois touros apresentaram maior intensidade das bandas 45 e $40 \mathrm{kDa}$, respectivamente. Os autores ressaltam a possibilidade da ausência de certas proteínas devido a sua incapacidade de ligação na membrana ou a sítios de ligação saturados, após a passagem do espermatozoide pelo epidídimo.

Roncoletta (1999) registrou grande variação na concentração total de proteínas do plasma seminal de touros, variando de 10 a $111 \mathrm{mg} / \mathrm{ml}$. Na comparação entre Bos taurus indicus e Bos taurus taurus, os zebuínos apresentaram, em média, $20 \%$ a mais de proteínas totais. A alta variabilidade na concentração de proteínas do plasma seminal de touros Nelore foi relatada também por Assunção et al. (2003) que registraram média de 13,5 mg/ml, com variação de 1,51 a 33 mg/ml. Mann \& Mann (1981) também relataram alta variabilidade de proteínas totais no homem e em várias espécies de animais domésticos. Para touros Nelore, Fernandes et al. (2009) identificaram oito bandas de proteínas HPB em touros Nelore variando entre 15 e $63 \mathrm{kDa}$. Duas proteínas com 22 e $25 \mathrm{kDa}$ foram similares às descritas em touros Bos taurus taurus. Outras proteínas identificadas com 39, 53, 58 e $63 \mathrm{kDa}$ ainda não foram descritas e possivelmente sejam específicas para Bos taurus indicus. Análises mais completas do proteoma de touros Bos taurus indicus foram publicadas por Rego et al. (2014) para touros Brahman e por Assumpção et al. (2002) para touros Nelore, utilizando espectrometria de massa (MALDI-ToF) e gel de eletroforese bidimensional para identificar diversos marcadores descritos na literatura para sêmen de mamíferos que agem ativamente nos processo de maturação, proteção, capacitação e fertilização.

\section{Associação de proteínas do sêmen com fertilidade e sucesso na criopreservação}

Com relação às associações de "pools" específicos de proteínas do sêmen com a fertilidade e congelação do sêmen, várias pesquisas tanto de proteínas do plasma seminal quanto de proteínas aderidas à membrana espermática têm sido conduzidas, com resultados às vezes conflitantes. Miller et al. (1990) buscando avaliar o papel das proteínas do sêmen de 14-18, 24 e $31 \mathrm{kDa}$ com afinidade a heparina sobre fertilidade, obtiveram dados contraditórios, uma vez que as proteínas isoladas foram ineficientes para estimular a membrana espermática e aumentar a reação acrossômica induzida. Todavia, Bellin et al. (1994) procuraram determinar a relação entre o grupo das HPB com a fertilidade de touros de corte das raças Red Angus, Santa Gertrudis e Gelbvieh. As proteínas foram identificadas por cromatografia (HPLC), em coluna com afinidade a heparina, sendo que nos lotes com a fertilidade testada, a diferença foi de até $17 \%$ para os touros com HPB na membrana espermática e não detectáveis 
no fluído seminal. Posteriormente, Bellin et al. (1998) demonstraram que a identificação das proteínas no sêmen de touros, principalmente a de $31 \mathrm{kDa}$ com afinidade a heparina, denominada "antígeno associado a fertilidade" (FAA), juntamente com as de 24 e $21,5 \mathrm{kDa}$, podem ser usadas como indicadores para alta fertilidade. Em testes de campo, agrupando touros pela presença de FAA, na razão touro:vaca de 1:25, os autores demonstraram até nove pontos percentuais de diferença na taxa de fertilidade entre os grupos. Na mesma linha de trabalhos, Sprott et al. (2000) avaliaram comparativamente a taxa de prenhez ao primeiro serviço em fêmeas inseminadas com sêmen de touros com e sem a FAA (31 kDa) na membrana espermática. Em fêmeas com estro espontâneo ou sincronizado, foi registrada diferença em torno de $16 \%$ a favor dos touros FAA positivos. Ao investigar pela primeira vez a influência de FAA sobre o sucesso na criopreservação do sêmen, Pande et al. (2019) mostraram que a presença de FAA na membrana está relacionado a um maior potencial de proteção contra o stress oxidativo, aumentando o potencial de acrossomas intactos vivos com boa função mitocondrial.

Diante da sugestão da influência do plasma seminal na fertilidade do macho em várias espécies e diferenças encontradas na fertilidade individual de touros de rebanhos leiteiros, Killian et al. (1993) se propuseram a analisar as proteínas do plasma seminal de 35 touros Holandeses. Os touros foram agrupados de acordo com a fertilidade alcançada pelos mesmos em inseminação artificial. O modelo de regressão das densitometrias das bandas de peso molecular, das quatro proteínas identificadas foi linear $(\mathrm{R} 2=0,89)$. Foram registradas duas proteínas $(55 \mathrm{kDa}$ e $4,8 \mathrm{pI} ; 26 \mathrm{kDa}$ e $6,4 \mathrm{pI})$ como as mais prevalentes entre os touros de alta fertilidade e duas outras ( $16 \mathrm{kDa}$ e $4,1 \mathrm{pI} ; 16 \mathrm{kDa}$ e $6,7 \mathrm{pI})$ predominantes em touros de baixa fertilidade. Alguns resultados mostram também que a predição da fertilidade pela análise das proteínas do sêmen poderia ser feita em touros jovens. Usando um modelo múltiplo de regressão linear, Killian et al. (1999) observaram correlação de 0,75 entre touros jovens e adultos e de 0,90 quando comparando touros de seis a doze meses de idade.

Chacur et al. (2003) não relataram associação de proteínas totais (PT) do sêmen com outros parâmetros andrológicos (Motilidade e defeitos espermáticos), porém citam algumas associações do quadro espermático com proteínas de 66, 55, 36 e $16 \mathrm{kDa}$. O mesmo para Assunção et al. (2003) que não registraram associações das proteínas do sêmen de bovinos com a fertilidade, mostrando que mesmo havendo alta variabilidade entre touros quanto ao total de proteínas no sêmen, são necessários exames detalhados sobre quais seriam essas proteínas para sua utilização como biomarcadores reprodutivos.

Marques et al. (2000) relataram uma proteína da membrana de 15,7 kDa que apresentou correlação significativa $(0,71)$ com a RAI e que poderia atuar como marcador para fertilidade em bovinos. Trabalhando com eletroforese bidimensional, Roncoletta (2003) relataram oito possíveis proteínas do plasma seminal e seis da membrana espermática que garantiriam a predição da fertilidade, podendo atuar como possíveis marcadores bioquímicos. A predição de congelamento do sêmen foi garantida por apenas duas proteínas do plasma seminal (18,2 kDa e pI 5,3; 17,9 kDa e pI 4,8), diferentes das proteínas associadas à fertilidade.

Apesar da expectativa promissora da identificação das FAA em raças taurinas e zebuínas, Dalton et al. (2012) não lograram êxito quando compararam as taxas de fertilidade de touros Nelores negativos e positivos para FAA quando os touros foram testados a campo com inseminação de tempo fixo. $\mathrm{O}$ trabalho levantou dúvidas quanto a utilização de kits comerciais para identificação desses antígenos, visando a seleção de touros Nelores de alto potencial fecundante.

Roncoletta (1999), estudando o perfil eletroforético das proteínas presentes no plasma seminal e na membrana do espermatozoide de touros zebuínos e europeus doadores de sêmen, observou que as bandas 45, 24 e 10,8 kDa apresentaram valores de densitometria significativamente maiores nos grupos de alta e média congelação; enquanto que, a proteína de 14,4 kDa apresentou maior valor nos de média e baixa. $\mathrm{O}$ autor também mostrou resultados de densitometria significativamente diferentes para as bandas 95, 58, 54, 45 e $36 \mathrm{kDa}$ entre os diferentes grupos. $\mathrm{O}$ resultado foi depois confirmado por Roncoletta et al. (2013) que demonstram desempenhos estatisticamente diferentes no congelamento do sêmen na comparação de alguns "spots" proteicos. Jobim et al. (2004) trabalhando também com eletroforese bidimensional, relataram que quatro proteínas foram superiores no plasma seminal de touros com alto padrão de congelamento do sêmen, sendo uma delas (16 kDa e pI 4,7-5,2) descritas 
inicialmente por Manjunath \& Sairam (1987) como a BSP A1/A2. As outras proteínas foram de 11-12 $\mathrm{kDa}$ e pI 4,8-4,9 identificada como aSFP, de 13-14 kDa e pI 4,0-4,5, e a de 20-22 kDa e pI 4,8-5,2 identificada como Clusterina. Contradizendo alguns dos trabalhos acima consultados, Roncoletta (2003) demonstrou que a osteopontina, a prostaglandina D-sintetase e a proteína BSP-A1/A2 não se apresentaram como potenciais marcadores bioquímicos para fertilidade ou congelabilidade do sêmen a partir da eletroforese bidimensional, relatando que somente a aSFP demonstrou potencial como marcador bioquímico para alto desempenho em fertilidade. Já a BSP-A3 (15kDa e pI 4,8-5,2) demostrou ser um potencial marcador para baixa fertilidade e congelamento. Na avaliação do perfil proteico de touros Nelore adultos as proteínas BSP-A3 e aSFP identificadas nas amostras mostraram grande potencial de predição da fertilidade dos reprodutores (Roncoletta et al., 2006). A aSFP foi 8,5 maior em touros com perfil de alta fertilidade e a BSP A3 foi 2,5 vezes maior. Os autores relatam que é claro o potencial das avaliações eletroforéticas de proteínas da membrana espermática na predição de touros Nelore de alta fertilidade. Em uma avaliação ampla dos perfis cromatográficos por gel filtração, afinidade a heparina e eletroforéticos de proteínas do plasma seminal e aderida à membrana espermática de touros jovens da raça Nelore, Salvador (2005) não obteve associação do perfil proteico com parâmetros andrológicos e congelação do sêmen apesar de identificarem várias das proteínas importantes já descritas na literatura. Não foram observadas associações entre as avaliações de proteínas do plasma seminal e aderidas a membrana. Entretanto, os autores concluem que alguns picos cromatográficos e proteínas identificadas $(14,18,21$ e 29, $56 \mathrm{kDa})$ foram eficazes na predição das taxas de reação acrossômica induzida, podendo atuar como marcadores bioquímicos para seleção de touros zebuínos visando alta fertilidade. No estudo houve a identificação de proteínas 28-29 kDa nos picos de maior afinidade das proteínas do plasma seminal e aderidas à membrana, que seriam as mesmas FAA descritas por Bellin et al. (1998). Da mesma forma, Magalhães Júnior et al. (2016) localizaram mais de duas formas de "Binder of SPerm 1 (BSP1)" em touros zebuínos adultos, e mostraram que nem todos os animais tinham a mesma abundância de BSP1 no plasma seminal. O trabalho também mostrou que algumas BSP1 estavam associadas aos touros de alto congelamento do sêmen, e outras aos de baixa congelamento, em função das diferenças entre seus pesos moleculares.

$\mathrm{Na}$ literatura científica atual existe uma forte tendência na busca de marcadores fisiológicos e bioquímicos, que atuem como coadjuvantes para seleção de touros para alta fertilidade e congelamento do sêmen, visando maior acurácia na predição da fertilidade de reprodutores bovinos, tanto a campo, quanto nos processos de FIV. Dentre estes biomarcadores, as BSP apresentam-se como possíveis testes para marcadores de alta fertilidade e congelamento do sêmen. Esse conjunto de proteínas está envolvido em diferentes passos do processo de fertilização, talvez o principal deles a capacitação espermática. Da mesma forma, existem biomarcadores associados negativamente à fertilidade e sucesso na criopreservação do sêmen, como por exemplo, a ubiquitina, que pode estar associados a problemas espermáticos, além de outros marcadores para diagnóstico de touros andrologicamente normais, mas com baixo desempenho na fecundação ou criopreservação (Kumar et al., 2012; Sutovsky et al., 2001).

\section{Considerações finais e perspectivas futuras}

A utilização de técnicas mais sofisticadas (espectrômetro de massa e sequenciamento N-terminal) para identificação proteoma do touro poderá fornecer subsídios importantes na comparação com os relatos da literatura, confirmando algumas das suposições levantadas durante as discussões. Vislumbrase a possibilidade futura de seleção de touros para alta fertilidade pela identificação de biomarcadores no sêmen, o que pode ser viabilizado para exames de rotina com elaboração de kits de imuno identificação para estes biomarcadores. Os novos testes e avaliações bioquímicas do plasma seminal ressaltam que a capacidade de fecundação espermática é um aspecto multifatorial, ou seja, dificilmente será explicada ou identificada por um único exame, marcador biomolecular ou processo fisiológico. Mesmo as avaliações do proteoma seminal ou grupo de proteínas ligadas à membrana espermática (BSP) devem ser considerados somente como uma parte do entendimento dos complexos mecanismos envolvidos preparação do espermatozoide para fecundação. Cabem às futuras pesquisas da área, aprofundar e entender cada vez mais quais são esses multifatores, suas relações e o quanto eles afetam os processos reprodutivos de touros. Um olhar mais amplo em relação aos mais de 50 anos de pesquisas sobre o potencial fecundante dos espermatozoides, nos mostra que ainda temos um logo caminho a 
percorrer quanto ao entendimento dos complexos fatores envolvidos na preparação do gameta masculino para uma fertilização de sucesso.

O impacto dessas pesquisas para agropecuária vão desde o melhoramento genético para reprodução de diversas espécies e raças, melhoria nas condições de manejo e aplicação de biotecnologias da reprodução, até as possibilidades de correção de determinados problemas reprodutivos de animais que estão aparentemente saudáveis do ponto de vista reprodutivo, mas enfrentam problemas específicos para os processos de criopreservação do sêmen ou utilização em técnicas de FIV.

\section{Referências bibliográficas}

Assumpção, M. E. O. D. A., Haipeck, K., Lima, A. S., Mello, M. R. B., Oliveira, L. J., Oliveira, V. P. \& Visintin, J. A. (2002). Capacitação espermática in vitro com heparina e cálcio ionóforo e sua correlação com a fertilidade em touros. Brazilian Journal of Veterinary Research and Animal Science, 39(3):149-156.

Assunção, T. I., Fontes, W., Souza, M. V. \& Ricart, C. A. O. (2003). Perfil de proteínas do plasma seminal de touros Nelore e sua relação com a fertilidade. Revista brasileira de Reprodução Animal, 27(2):187-188.

Ax, R. L., Hawkins, S. K. \& Denise, T. R. (2002). New developments in managing the bull. In M. J. Fields, R. S. Sand \& J. V. Yelich (Eds.), Factors affecting calf crop: Biotechnology of reproduction (pp. 287-296). USA: Boca Raton.

Ax, R. L. \& Lenz, R. W. (1987). Glycosaminoglycans as probes to monitor differences in fertility of bulls. Journal of Dairy Science, 70(7):1477-1486.

Bellin, M. E., Hawkins, H. E. \& Ax, R. L. (1994). Fertility of range beef bulls grouped according to presence or absence of heparin-binding proteins in sperm membranes and seminal fluid. Journal of Animal Science, 72(9):2441-2448.

Bellin, M. E., Oyarzo, J. N., Hawkins, H. E., Zhang, H., Smith, R. G., Forrest, D. W. \& Ax, R. L. (1998). Fertility-associated antigen on bull sperm indicates fertility potential. Journal of Animal Science, 76(8):2032-2039.

Blottner, S., Nehring, H. \& Torner, H. (1990). Individual differences in capacitation of bull spermatozoa by heparin in vitro: relationship to fertility. Theriogenology, 34(3):619-628.

Camargo, L. S. A., Sá, W. F., Ferreira, A. M., Viana, J. H. M. \& Araújo, M. C. C. (2002). Efeito de concentração espermática e período de incubação oócito-espermatozóides na fecundação in vitro em bovinos da raça Gir. Pesquisa Agropecuária Brasileira, 37(5):709-715.

Cancel, A. M., Chapman, D. A. \& Killian, G. J. (1997). Osteopontin is the 55-kilodalton fertilityassociated protein in Holstein bull seminal plasma. Biology of Reproduction, 57(6):1293-1301.

Chacur, M. G. M., Rabesquine, M. M. \& Machado Neto, N. B. (2003). Seleção da fertilidade em touros e proteínas do plasma seminal: correlação com o quadro espermático. Revista Brasileira de Reprodução Animal, 27185-186.

Dacheux, J.-L. \& Dacheux, F. (2002). Protein secretion in the epididymis The epididymis: from molecules to clinical practice: Springer.

Dalton, J. C., Deragon, L., Vasconcelos, J. L. M., Lopes, C. N., Peres, R. F. G. \& Ahmadzadeh, A. (2012). Fertility-associated antigen on Nelore bull sperm and reproductive outcomes following firstservice fixed-time AI of Nelore cows and heifers. Theriogenology, 77(2):389-394.

Desnoyers, L. \& Manjunath, P. (1992). Major proteins of bovine seminal plasma exhibit novel interactions with phospholipid. Journal of Biological Chemistry, 267(14):10149-10155.

Druart, X. \& Graaf, S. (2018). Seminal plasma proteomes and sperm fertility. Animal Reproduction Science, 19433-40.

Einspanier, R., Einspanier, A., Wempe, F. \& Scheit, K. H. (1991). Characterization of a new bioactive protein from bovine seminal fluid. Biochemical and Biophysical Research Communications, 179(2):1006-1010. 
Fazeli, A. R., Steenweg, W., Bevers, M. M. \& Colenbrander, B. (1993). Development of a sperm zona pellucida binding assay for bull semen. The Veterinary Record, 132(1):14-16.

Fernandes, C. E., Souza, F. F., Souza-Neto, J. A. \& Ribola, P. E. M. (2009). Heparin-binding proteins of seminal plasma in Nellore bulls. Ciência Rural, 39(1):275-278.

Florman, H. M. \& First, N. L. (1988). The regulation of acrosomal exocytosis: I. Sperm capacitation is required for the induction of acrosome reactions by the bovine zona pellucida in vitro. Developmental Biology, 128(2):453-463.

Garner, D. L. (1997). Ancillary tests of bull semen quality. Veterinary Clinics of North America: Food Animal Practice, 13(2):313-330.

Gatti, J. L., Castella, S., Dacheux, F., Ecroyd, H., Metayer, S., Thimon, V. \& Dacheux, J. L. (2004). Post-testicular sperm environment and fertility. Animal Reproduction Science, 82321-339.

Gerena, R. L., Irikura, D., Urade, Y., Eguchi, N., Chapman, D. A. \& Killian, G. J. (1998). Identification of a fertility-associated protein in bull seminal plasma as lipocalin-type prostaglandin D synthase. Biology of Reproduction, 58(3):826-833.

Hafez, B. \& Hafez, E. (2004). Reprodução Animal (Vol. 1, pp. 513): Manole: São Paulo, Brasil.

Handrow, R. R., Boehm, S. K., Lenz, R. W., Robinson, J. A. \& Ax, R. L. (1984). Specific binding of the glycosaminoglycan $3 \mathrm{H}$-heparin to bull, monkey, and rabbit spermatozoa in vitro. Journal of Andrology, 5(2):51-63.

Jobim, M. I. M., Oberst, E. R., Salbego, C. G., Souza, D. O., Wald, V. B., Tramontina, F. \& Mattos, R. C. (2004). Two-dimensional polyacrylamide gel electrophoresis of bovine seminal plasma proteins and their relation with semen freezability. Theriogenology, 61(2-3):255-266.

Killian, G. J., Chapman, D. A., Cancel, A. M., Gerena, R. L., Rodriquez, C. M. \& Day, J. R. (1999). Male factors affecting sperm fertility. Revista Brasileira de Reprodução Animal, 23(2):83-85.

Killian, G. J., Chapman, D. A. \& Rogowski, L. A. (1993). Fertility-associated proteins in Holstein bull seminal plasma. Biology of Reproduction, 49(6):1202-1207.

Kitiyanant, Y., Chaisalee, B. \& Pavasuthipaisit, K. (2002). Evaluation of the acrosome reaction and viability in buffalo spermatozoa using two staining methods: the effects of heparin and calcium ionophore A23187. International journal of Andrology, 25(4):215-222.

Kopf, G. S. (1999). Acrossome reaction. Encyclopedia of Reproduction, 117-25.

Kumar, P., Kumar, D., Singh, I. \& Yadav, P. S. (2012). Seminal plasma proteome: promising biomarkers for bull fertility. Agricultural Research, 1(1):78-86.

Lane, M. E., Therien, I., Moreau, R. \& Manjunath, P. (1999). Heparin and high-density lipoprotein mediate bovine sperm capacitation by different mechanisms. Biology of Reproduction, 60(1):169175.

Lee, C. N., Handrow, R. R., Lenz, R. W. \& Ax, R. L. (1985). Interactions of seminal plasma and glycosaminoglycans on acrosome reactions in bovine spermatozoa in vitro. Gamete Research, 12(4):345-355.

Lonergan, P. (1994). The application of in vitro fertilization techniques to the prediction of bull fertility. Reproduction in Domestic Animals, 29(1):12-21.

Magalhães Júnior, M. J., Martins, L. F., Senra, R. L., Santos, T. F., Okano, D. S., Pereira, P. R. G., . . Baracat-Pereira, M. C. (2016). Differential abundances of four forms of Binder of SPerm 1 in the seminal plasma of Bos taurus indicus bulls with different patterns of semen freezability. Theriogenology, 86(3):766-777.

Manjunath, P., Chandonnet, L., Leblond, E. \& Desnoyers, L. (1994). Major proteins of bovine seminal vesicles bind to spermatozoa. Biology of Reproduction, 50(1):27-37.

Manjunath, P. \& Sairam, M. R. (1987). Purification and biochemical characterization of three major acidic proteins (BSP-A1, BSP-A2 and BSP-A3) from bovine seminal plasma. Biochemical Journal, 241(3):685-692. 
Manjunatha, H. \& Srinivasan, K. (2006). Protective effect of dietary curcumin and capsaicin on induced oxidation of low-density lipoprotein, iron-induced hepatotoxicity and carrageenan-induced inflammation in experimental rats. The FEBS Journal, 273(19):4528-4537.

Mann, T. \& Mann, C. L. (1981). Male reproductive function and semen. New York, USA: SpringerVerlag.

Marques, V. A., Goulart, L. R. \& Silva, A. E. D. (2000). Variations of protein profiles and calcium and phospholipase A2 concentrations in thawed bovine semen and their relation to acrosome reaction. Genetics and Molecular Biology, 23(4):825-829.

Maxwell, W. M. C., Graaf, S. P., Ghaoui, R. H. \& Evans, G. (2007). Seminal plasma effects on sperm handling and female fertility. Society of Reproduction and Fertility, 6413-38.

McCauley, T. C., Zhang, H., Bellin, M. E. \& Ax, R. L. (1999). Purification and characterization of fertility-associated antigen (FAA) in bovine seminal fluid. Molecular Reproduction and Development: Incorporating Gamete Research, 54(2):145-153.

Miller, D. J., Winer, M. A. \& Ax, R. L. (1990). Heparin-binding proteins from seminal plasma bind to bovine spermatozoa and modulate capacitation by heparin. Biology of Reproduction, 42(5-6):899915.

Ollero, M., Bescos, O., Cebrian-Perez, J. A. \& Muino-Blanco, T. (1998). Loss of plasma membrane proteins of bull spermatozoa through the freezing-thawing process. Theriogenology, 49(3):547-555.

Pande, M., Srivastava, N., Kumar, S., Soni, Y. K., Kumar, M., Tyagi, S., . . Arya, S. (2019). Greater potentiality of sperm membrane bound fertility associated antigen to withstand oxidative stress ensuing improved sperm function of cryopreserved bull spermatozoa. Indian Journal of Animal Research, 53(5):572-577.

Parrish, J. J., Susko-Parrish, J. L., Handrow, R. R., Sims, M. M. \& First, N. L. (1989). Capacitation of bovine spermatozoa by oviduct fluid. Biology of Reproduction, 40(5):1020-1025.

Parrish, J. J., Susko-Parrish, J. L., Winer, M. A. \& First, N. L. (1988). Capacitation of bovine sperm by heparin. Biology of Reproduction, 38(5):1171-1180.

Ratner, N., Bunge, R. P. \& Glaser, L. (1985). A neuronal cell surface heparan sulfate proteoglycan is required for dorsal root ganglion neuron stimulation of Schwann cell proliferation. The Journal of Cell Biology, 101(3):744-754.

Rego, J. P. A., Crisp, J. M., Moura, A. A., Nouwens, A. S., Li, Y., Venus, B., Corbet, N. J., Corbet, D. H., Burns, B. M., Boe-Hansen, G. B. \& McGowan, M. R. (2014). Seminal plasma proteome of electroejaculated Bos indicus bulls. Animal Reproduction Science, 148(1-2), 1-17.

Rickard, J. P., Pool, K. R., Druart, X. \& Graaf, S. P. (2019). The fate of spermatozoa in the female reproductive tract: A comparative review. Theriogenology, 137104-112.

Rodriguez-Martinez, H., Larsson, B., Zhang, B. R. \& Soderquist, L. (1997). In vitro assessment of viability and fertilizing capacity of bull spermatozoa. The Journal of Reproduction and Development, 43(1):1-11.

Rodríguez-Martínez, H., Kvist, U., Ernerudh, J., Sanz, L. \& Calvete, J. J. (2011). Seminal plasma proteins: what role do they play? American Journal of Reproductive Immunology, 6611-22.

Roncoletta, M. (1999). Perfil em "SDS - page" das proteínas de espermatozóides e plasma seminal relacionados com a congelabilidade do sêmen de touros. Master of Science, Universidade do Estado de São Paulo, Jaboticabal, São Paulo, Brasil.

Roncoletta, M. (2003). Perfil bidimensional de proteínas de membrana de espermatozóides e plasma seminal, relacionados com a fertilidade e com a congelabilidade do sêmen de touros. $\mathrm{PhD}$, Universidade do Estado de São Paulo, Jaboticabal, São Paulo, Brasil.

Roncoletta, M., Morani, E. d. S. C., Esper, C. R., Barnabe, V. H. \& Franceschini, P. H. (2006). Fertilityassociated proteins in Nelore bull sperm membranes. Animal Reproduction Science, 91(1-2):77-87.

Roncoletta, M., Morani, E. S. C., Rodrigues, L. H. \& Francheschini, P. H. (2013). Proteômica para investigar a congelabilidade do semen bovino. Brazilian Journal of Veterinary Research and Animal Science, 50(1):43-49. 
Salvador, D. F. (2005). Perfis cromatográfico e eletroforético de proteínas com afinidade à heparina do sêmen de touros jovens da raça Nelore e suas associações com a seleção andrológica, congelação do sêmen e reação acrossômica induzida. PhD, Universidade Federal de Minas Gerais, Belo Horizonte, Minas Gerais, Brasil.

Sprott, L. R., Harris, M. D., Forrest, D. W., Young, J., Zhang, H. M., Oyarzo, J. N. \& Ax, R. L. (2000). Artificial insemination outcomes in beef females using bovine sperm with a detectable fertilityassociated antigen. Journal of Animal Science, 78(4):795-798.

Suarez, S. S. (2016). Mammalian sperm interactions with the female reproductive tract. Cell and Tissue Research, 363(1):185-194.

Sutovsky, P., Kerns, K., Zigo, M. \& Zuidema, D. (2019). Boar semen improvement through sperm capacitation management, with emphasis on zinc ion homeostasis. Theriogenology, 13750-55.

Sutovsky, P., Terada, Y. \& Schatten, G. (2001). Ubiquitin-based sperm assay for the diagnosis of male factor infertility. Human Reproduction, 16(2):250-258.

Therien, I., Bleau, G. \& Manjunath, P. (1995). Phosphatidylcholine-binding proteins of bovine seminal plasma modulate capacitation of spermatozoa by heparin. Biology of Reproduction, 52(6):13721379.

Therien, I., Soubeyrand, S. \& Manjunath, P. (1997). Major proteins of bovine seminal plasma modulate sperm capacitation by high-density lipoprotein. Biology of Reproduction, 57(5):1080-1088.

Wassarman, P. M. (1988). Zona pellucida glycoproteins. Annual Review of Biochemistry, 57(1):415442.

Yanagimachi, R. (1988). Mechanisms of fertilization in mammals. In L. Mastroianni \& J. D. Biggers (Eds.), Fertilization and embryonic development In Vitro (pp. 81-183). New York, USA: Plenum Press.

Recebido: 30 de setembro, 2019.

Aprovado: 22 de outubro, 2019.

Publicado: 28 de outubro, 2019.

Licenciamento: Este artigo é publicado na modalidade Acesso Aberto sob a licença Creative Commons Atribuição 4.0 (CC-BY 4.0), a qual permite uso irrestrito, distribuição, reprodução em qualquer meio, desde que o autor e a fonte sejam devidamente creditados. 